\title{
Magnetism and Structure Evolution in Ni-Zn Ferrites Thin Films - CEMS Study
}

T. Szumiata ${ }^{a, *}$, M. Gzik-Szumiata ${ }^{a}$, K. BrzózkA $^{a}$, B. Górka ${ }^{a}$, M. Gawroński $^{a}$, A. JAVED ${ }^{b}$, K. FARMAN ${ }^{b}$ AND T. FATIMA ${ }^{b}$

${ }^{a}$ Department of Physics, Faculty of Mechanical Engineering, University of Technology and Humanities in Radom, J. Krasickiego 54, 26-600 Radom, Poland

${ }^{b}$ Department of Physics, University of the Punjab, Quaid-i-Azam Campus, Lahore-54590, Pakistan

In this work, a ${ }^{57} \mathrm{Fe}$ conversion electron Mössbauer spectrometry and X-ray diffraction have been utilized in order to investigate the structural and magnetic order in $500 \mathrm{~nm}$ thick Ni-Zn ferrite films deposited on $\mathrm{Si}(100)$ substrate by laser ablation. Considering the contributions of the conversion electron Mössbauer subspectra corresponding to the tetrahedral (A) and octahedral (B) sites, the spinel inversion parameter in $\left[\mathrm{Zn}_{x} \mathrm{Fe}_{1-x}\right]^{\mathrm{A}}\left[\mathrm{Ni}_{1-x} \mathrm{Fe}_{1+x}\right]^{\mathrm{B}} \mathrm{O}_{4}$ films has been estimated. The hyperfine field $\left(B_{h f}\right)$ values in the investigated $\mathrm{Ni}-\mathrm{Zn}$ ferrites thin films are about 5-8\% smaller than those of bulk ferrites, which could be a sign of thermal magnetic relaxations due to the size effects. The distribution of hyperfine magnetic field directions was found to be affected by perpendicular anisotropy.

DOI: 10.12693/APhysPolA.131.836

PACS/topics: 76.80.+y, 81.15.Fg, 81.05.Je

\section{Introduction}

$\mathrm{Ni}-\mathrm{Zn}$ ferrites are promising ceramic materials for microwave and pulsed applications due to the ability of fast magnetization changes $[1,2]$. The structural and magnetic order were effectively studied by means of transmission Mössbauer spectrometry in bulk [3$6]$ and nanocrystalline $[7,8] \mathrm{Ni}-\mathrm{Zn}$ ferrites. In this work, a conversion electron Mössbauer spectrometry (CEMS) and X-ray diffraction (XRD) have been utilized for the investigation of structural and magnetic order in $500 \mathrm{~nm}$ thick $\mathrm{Ni}_{1-x} \mathrm{Zn}_{x} \mathrm{Fe}_{2} \mathrm{O}_{4}(0 \leq x \leq 1)$ ferrite films deposited on $\mathrm{Si}(100)$ substrate by laser ablation. The formula of $\mathrm{Ni}-\mathrm{Zn}$ ferrites could be denoted by $\left[\mathrm{Zn}_{x} \mathrm{Fe}_{1-x}\right]^{\mathrm{A}}\left[\mathrm{Ni}_{1-x} \mathrm{Fe}_{1+x}\right]^{\mathrm{B}} \mathrm{O}_{4}$, where $x$ is atomic percentage of $\mathrm{Zn}$. Symbols A and B represent the tetrahedral and octahedral sites in the spinel structure, respectively. Given formula is valid under assumption that all $\mathrm{Zn}$ atoms take only tetrahedral A sites (like in pure $\mathrm{ZnFe}_{2} \mathrm{O}_{4}$ which exhibits simple spinel structure), whereas $\mathrm{Ni}$ atoms occupy only octahedral B sites (like in pure $\mathrm{NiFe}_{2} \mathrm{O}_{4}$ having inverse spinel structure). The main goal of this work was to estimate the iron occupancies in A and B sites as a function of $\mathrm{Zn}$ content as well as pointing out any size effects related to the reduced dimensionality of $\mathrm{Ni}-\mathrm{Zn}$ ferrite thin films.

\section{Experimental}

$\mathrm{Ni}_{1-x} \mathrm{Zn}_{x} \mathrm{Fe}_{2} \mathrm{O}_{4}(0 \leq x \leq 1)$ ferrite films of thickness $500 \mathrm{~nm}$ were grown on $\mathrm{Si}(100)$ substrates using pulsed laser deposition (PLD). For each composition, the targets (diameter $=16 \mathrm{~mm}$ and thickness $=2 \mathrm{~mm}$ ) were prepared by standard ceramic method described elsewhere [9].

*corresponding author; e-mail: t.szumiata@uthrad.pl
Targets were mounted on the rotating holder which rotates with the speed of $2 \mathrm{rpm}$ to avoid non-uniform ablation and pitting. The pulse duration of 6 ns (with repetition rate of $10 \mathrm{~Hz}$ ) was used for deposition of each film. Before deposition, the base pressure of $\approx 10^{-7} \mathrm{~Pa}$ was achieved in PLD chamber. The deposition was carried-out under the continuous oxygen flow at the pressure of $10 \mathrm{~Pa}$. The target was ablated (for $300 \mathrm{~s}$ ) with 3000 laser shots at a repetition rate of $10 \mathrm{~Hz}$. The laser beam was focused with the help of plano-convex lens of focal length, $f=50 \mathrm{~cm}$ and was incident at the target surface at an angle of $45^{\circ}$ with respect to the normal. For all thin films, the laser fluence was kept constant at $15 \mathrm{~J} / \mathrm{cm}^{2}$. The ablated material was deposited on substrate placed $4 \mathrm{~cm}$ away from the target. All films were deposited at room temperature. Film of each composition was deposited under similar deposition conditions. The deposition time of $300 \mathrm{~s}$ provides the film thickness of $500 \mathrm{~nm}$, which was confirmed using atomic force microscopy (AFM). After deposition, all films were annealed (at $900^{\circ} \mathrm{C}$ for $3 \mathrm{~h}$ ) in air furnace to avoid the amorphous phases in the films.

For all films, the structure and phase analysis was studied by X-ray diffraction (XRD). Philips X-ray diffractometer (PANalytical X'PERT PRO: $\mathrm{Cu} K_{\alpha}$ radiation) operating at $40 \mathrm{kV}$ and $40 \mathrm{~mA}$ was employed. All XRD patterns were taken at grazing angle of $5^{\circ}$ in the range of $2 \theta=30$ to $75^{\circ}$ with a step size $=0.02^{\circ}$ and acquisition time $=5 \mathrm{~s}$ per step.

For the examination of structural and magnetic order ${ }^{57} \mathrm{Fe}$-based CEMS was utilized at room temperature. The spectra have been fitted with PolMoss package (for MS Excel with Solver extension) which was successfully applied e.g. in the case of $\mathrm{Fe}-\mathrm{Ga}$ thin films [10]. The fitted subspectra were represented by the Voigt-type profile as a convolution of Lorentzian base lines with Gaussian distributions of hyperfine parameters both in doublets and the Zeeman sextets. 


\section{Results and discussion}

Figure 1a shows the XRD patterns of $\mathrm{Ni}_{1-x} \mathrm{Zn}_{x} \mathrm{Fe}_{2} \mathrm{O}_{4}$ $(x=0)$ ferrite films. For all films, the observed peaks belong to the single (cubic) phase. Up to $x=0.6$, the films had (311) texture normal to the film plane. For $x=0.8$ and $x=1$, the films exhibited dominant texture along (422) and (511) crystallographic directions, respectively. Further, the increase in Zn-concentration resulted in peak shift towards the lower $2 \theta$ angle in the $\mathrm{Ni}-\mathrm{Zn}$ ferrite thin films which was expected due to greater ionic radius $(0.74 \AA)$ of $\mathrm{Zn}^{2+}$ ions as compared with the ionic radii of $\mathrm{Ni}^{2+}$ ion $(0.6 \AA)$ and $\mathrm{Fe}^{2+}$ ion $(0.61 \AA)[11,12]$. By measuring the peaks position, the lattice constants of all thin films were calculated using the relation: $\sin ^{2} \theta=\lambda^{2}\left(h^{2}+k^{2}+l^{2}\right) / 4 a^{2}$, where $a$ is the lattice constant, $\theta$ is the angle of diffraction, $\lambda$ is the wavelength of X-ray beam and $(h k l)$ represent the Miller indices of plane from which the reflection occurs. Figure $1 \mathrm{~b}$ shows the lattice constant as a function of $\mathrm{Zn}$ concentration (wt\%) for $\mathrm{Ni}_{1-x} \mathrm{Zn}_{x} \mathrm{Fe}_{2} \mathrm{O}_{4}$ ferrite thin films. The lattice constant increased with $\mathrm{Zn}$ content similar to their bulk counterpart. Our thin film data were found to agree with the bulk lattice constants. This could be due to the fact that the films were not very thin $(0.5 \mu \mathrm{m})$ having lattice constants almost equal to the bulk lattice constants [13].
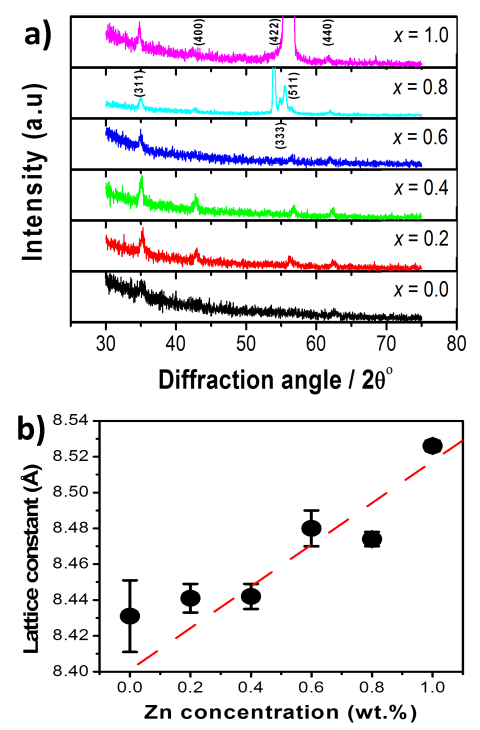

Fig. 1. (a) XRD patterns of $\mathrm{Ni}_{1-x} \mathrm{Zn}_{x} \mathrm{Fe}_{2} \mathrm{O}_{4}$ thin films and (b) lattice constant as a function of $\mathrm{Zn}$ concentration.

In Fig. 2 CEMS spectra for $\mathrm{Ni}_{1-x} \mathrm{Zn}_{x} \mathrm{Fe}_{2} \mathrm{O}_{4}$ ferrites of different $\mathrm{Zn}$ content are presented. The statistic of spectra is limited due to the small surface of layers. When $x=0$ (a) the spectrum is typical of the ferromagnetic inverse $\mathrm{NiFe}_{2} \mathrm{O}_{4}$ spinel and consist of two Zeeman sextets $\mathrm{A}$ and B0, corresponding to tetrahedral A and octahedral $\mathrm{B}$ sites of $\mathrm{Fe}$, respectively. In most of the references the sextet of higher hyperfine field is attributed to B po- sition [3-5] for $x<0.4$. In general obtained values of hyperfine fields $B_{h f}$ (Table I) are lower by $5-8 \%$ than those reported in literature [3-6] for respective bulk materials, which is a sign of thermal magnetic relaxation effects in thin layers - like in the case of $\mathrm{Ni}-\mathrm{Zn}$ ferrites nanoparticles [7, 8].
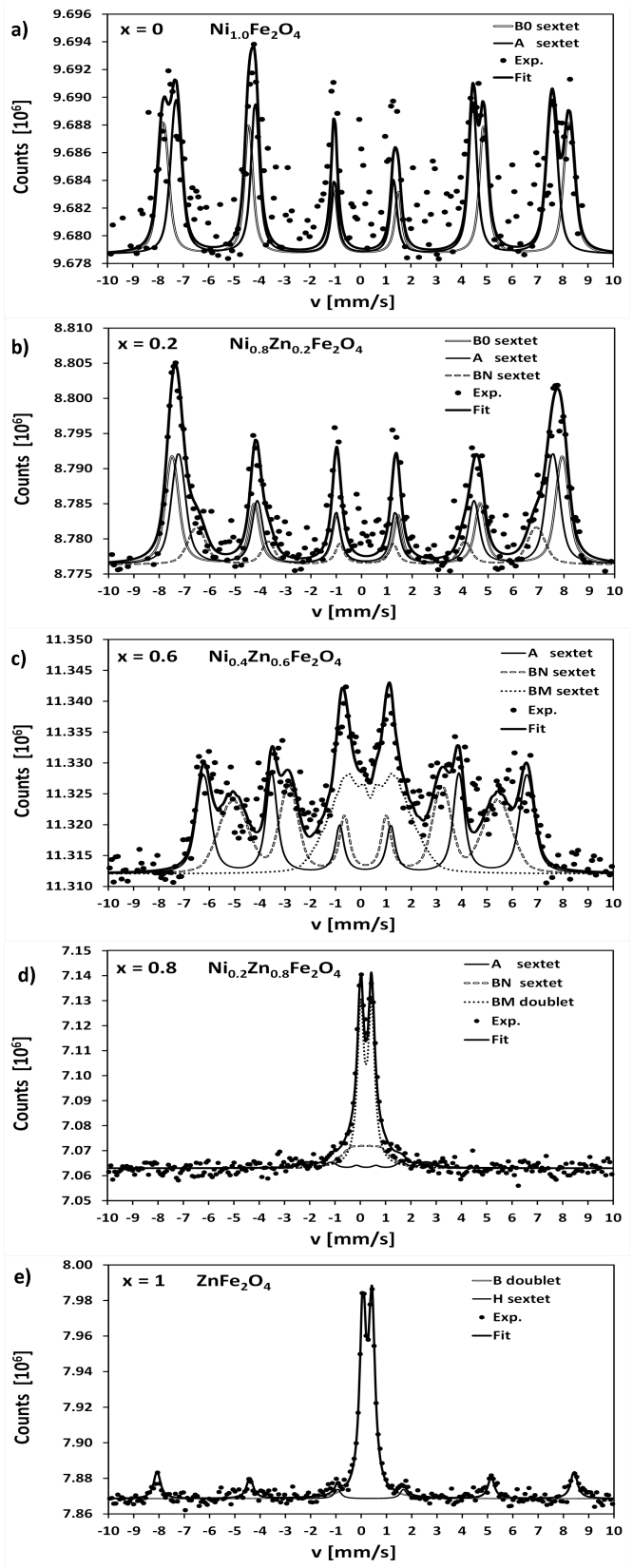

Fig. 2. CEMS spectra for $\mathrm{Ni}_{1-x} \mathrm{Zn}_{x} \mathrm{Fe}_{2} \mathrm{O}_{4}$ thin films grown on $\mathrm{Si}(100)$ substrate.

In CEMS spectrum obtained for $x=0.2$ zinc content besides $\mathrm{B} 0$ and $\mathrm{A}$ sextets (with small variance $\Delta B_{h f}$ of hyperfine field distribution) the broadened sextet BN occurs which corresponds to the iron in B sites possessing $n=1-3 \mathrm{Zn}$ neighbors in the nearest A sites (instead of $\mathrm{Fe}$ ) [6]. When $x=0.6$ the B0 sextet $(n=0)$ is negligible, whereas a new, very broad sextet BM of low field arises, 
TABLE I

Hyperfine parameters of the individual components $G$ of the CEMS spectra for $\mathrm{Ni}_{1-x} \mathrm{Zn}_{x} \mathrm{Fe}_{2} \mathrm{O}_{4}$ thin films on $\mathrm{Si}(100)$ substrate. The estimated uncertainties of hyperfine parameters do not exceed the last given decimal position.

\begin{tabular}{c|c|c|c|c|c|c|c}
\hline \hline$x$ & $G$ & $I S$ & $Q S$ & $B_{h f}$ & $\Delta B_{h f}$ & $p$ & $r$ \\
\cline { 3 - 6 } & & {$[\mathrm{mm} / \mathrm{s}]$} & \multicolumn{2}{|c}{$[\mathrm{T}]$} & {$[\%]$} & \\
\hline \multirow{2}{*}{0} & B0 sextet & 0.35 & 0.00 & 50.0 & 0.9 & 46 & \multirow{2}{*}{2.4} \\
& A sextet & 0.26 & 0.00 & 46.3 & 0.9 & 54 & \\
\hline \multirow{4}{*}{0.2} & B0 sextet & 0.34 & 0.00 & 48.0 & 1.0 & 40 & \\
& A sextet & 0.27 & 0.00 & 46.0 & 1.1 & 43 & \multirow{2}{*}{1.4} \\
& BN sextet & 0.31 & 0.00 & 41.8 & 1.6 & 17 & \\
\hline \multirow{4}{*}{0.6} & A sextet & 0.29 & 0.00 & 39.9 & 1.2 & 31 & \\
& BN sextet & 0.30 & 0.00 & 32.6 & 3.0 & 40 & 2.5 \\
& BM sextet & 0.48 & 0.00 & 8.7 & 3.5 & 29 & \\
\hline \multirow{4}{*}{0.8} & A sextet & 0.35 & 0.00 & 15.0 & 1.5 & 8 & \\
& BN sextet & 0.32 & 0.00 & 5.0 & 2.5 & 24 & 3.0 \\
& BM doublet & 0.34 & 0.43 & - & - & 68 & \\
\hline \multirow{2}{*}{1.0} & B doublet & 0.36 & 0.36 & - & - & 76 & \multirow{2}{*}{2.2} \\
& H sextet & 0.39 & -0.20 & 51.4 & 0.2 & 24 & \\
& & & & & & &
\end{tabular}

corresponding to $n=4-6$. In the case of $x=0.8$ the exchange magnetic interactions in $\mathrm{B}$ site are so weakened that the $\mathrm{BM}$ sextet transforms into paramagnetic doublet. When $x=1$ (pure $\mathrm{ZnFe}_{2} \mathrm{O}_{4}$ thin film) the spectrum predominantly consists of the doublet (attributed to paramagnetic Fe ions at B site) of quadrupole splitting QS (Table I) very close to the value for bulk ferrites [6]. Additionally, the Zeeman sextet $H$ of more than $20 \%$ contribution is visible. Its values of hyperfine field, quadrupole splitting and isomer shift (IS relative to Fe foil standard) correspond to hematite (formed at the partially oxidized surface of thin film). For $x=0-0.8$ all magnetic components in the spectra revealed negligible quadrupole splitting (both for A and B sites). According to Ref. [4] the reason is not the absence of local electric field gradient, but its averaging out in magnetically coupled spin system due to chemical and structural disorder.

TABLE II

Theoretical $(t h)$ and experimental $(e x)$ spinel inversion parameter $i$ of $\mathrm{Ni}_{1-x} \mathrm{Zn}_{x} \mathrm{Fe}_{2} \mathrm{O}_{4}$ thin films as a function of $\mathrm{Zn}$ content $x$.

\begin{tabular}{c|c|c|c|c|c}
\hline \hline$x$ & 0 & 0.2 & 0.6 & 0.8 & 1.0 \\
\hline$i_{\text {th }}=(1-x) /(1+x)$ & 1.00 & 0.67 & 0.25 & 0.11 & 0.00 \\
$i_{e x}=p(\mathrm{~A}) / p(\mathrm{~B})$ & 1.17 & 0.74 & 0.45 & 0.09 & 0.00
\end{tabular}

Referring to the general formula of $\mathrm{Ni}-\mathrm{Zn}$ ferrites given in Sect. 1, one can define theoretical inversion parameter of the spinel as: $i_{t h}=(1-x) /(1+x)$. Experimental value of this parameter can be estimated as $i_{e x}=p(\mathrm{~A}) / p(\mathrm{~B})$, where $p(\mathrm{~A})$ is the contribution of $\mathrm{A}$ sextet, whereas $p(\mathrm{~B})$ is the sum of contributions of components corresponding to B sites. For $x=0-0.6$ the values of $i_{e x}$ exceed noticeably $i_{t h}$ (Table II). Presumably it is caused by the vacancies in $B$ sites and by the fact that some amount of $\mathrm{Zn}$ atoms takes not only A sites but also B ones. This phenomenon was observed at low temperatures in bulk
$\mathrm{Ni}-\mathrm{Zn}$ ferrites [8], however in the case of thin films one can expect it even at room temperature due to the influence of substrate at the structural disorder. Moreover, not ideally equal Debye-Waller factors for $\mathrm{Fe}$ in $\mathrm{A}$ and B positions could influence $i_{e x}$ estimation. The observed distribution of $B_{h f}$ direction is not isotropic, which could be caused by the reduced dimensionality. The $r$ ratio of the second to third line amplitude in Zeeman sextets (Table I) points to the transition from perpendicular anisotropy for $x=0.2(r \ll 2)$ to in-plane anisotropy for $x=0.8(r \gg 2)$ due to the evolution of internal strain and magnetostriction constant.

\section{Conclusions}

In conclusion, XRD and CEMS outcomes confirm the high quality of $\mathrm{Ni}-\mathrm{Zn}$ ferrites thin films (prepared with laser ablation and annealed). In the whole range of $\mathrm{Zn}$ concentration no amorphous phase has been detected. Though main properties of the films are similar to the bulk ferrites, some size effects such as thermal magnetic relaxation, the change of spinel inversion parameter, structural and chemical disorder as well as perpendicular magnetic anisotropy have been noticed. The obtained thin layers are good candidates for applications in microwaves and pulsed devices.

\section{References}

[1] N. Chen, M. Gu, Open J. Met. 2, 37 (2012).

[2] R.S. Shinde, P. Pareek, R.R. Yadav, in: Proc. 3rd Asian Particle Acceler. Conf., Gyeongju (Korea), Eds.: W. Namkung, S. Baik, Pohang, Gyeongju 2004, p. 702 .

[3] V.I. Goldanskii, V.F. Belov, M.N. Devisheva, V.A. Trukhtanov, Zh. Eksp. Teor. Fiz. 22, 1149 (1966).

[4] J.M. Daniels, A. Rosencwaig, Canad. J. Phys. 48, 381 (1970).

[5] L.K. Leung, B.J. Evans, A.H. Morrish, Phys. Rev. $B$ 8, 29 (1973).

[6] M. Arshed, M. Siddique, M. Anwar-ul-Islam, N.M. Butt, T. Abbas, M. Ahmed, Solid State Commun. 93, 599 (1995).

[7] M. Niyaifar, H. Mohammadpour, A.F.R. Rodriguez, J. Magn. 20, 246 (2015).

[8] A.P. Kazin, M.N. Rumyantseva, V.E. Prusakov, I.P. Suzdalev, A.M. Gaskov, Inorg. Mater. 48, 525 (2012).

[9] K. Farman, M.Sc. Thesis, University of the Punjab, Lahore-Pakistan 2014.

[10] T. Szumiata, K. Brzózka, M. Gawroński, B. Górka, A. Javed, N.A. Morley, M.R.J. Gibbs, Acta Phys. Pol. A 119, 21 (2011).

[11] A. Sutka, G. Strikis, G. Mezinskis, A. Lusis, J. Zavickis, J. Kleperis, D. Jakovlevs, Thin Solid Films $\mathbf{5 2 6}$ 65 (2012).

[12] Q. Liu, L. Lv, J.P. Zhou, X.M. Chen, X.B. Bian, P. Liu, J. Ceram. Process. Res. 13, 110 (2012).

[13] K.R. Krishna, K.V. Kumar, D. Ravinder, Adv. Mater. Phys. Chem. 2, 185 (2012). 